\title{
DESIGN ZOLMITRIPTAN LIQUISOLID ORODISPERSIBLE TABLETS AND THEIR IN VITRO EVALUATION
}

\author{
MUSTAFA EGLAa, SHAIMAA N. ABD AL HAMMIDb \\ aAL-Habboobi General Hospital, Thi-Qar Health Directorate, Ministry of Health, Thi-qar, Iraq, ${ }^{b}$ Department of Pharmaceutics, College of \\ Pharmacy, University of Baghdad, Baghdad, Iraq \\ Email: nu8641@yahoo.com
}

Received: 13 Oct 2016 Revised and Accepted: 26 Nov 2016

\begin{abstract}
Objective: The objective of present study is to develop orodispersible tablets (ODTs) of zolmitriptan by liquisolid technique using different types of super disintegrants to enhance the disintegration and dissolution of zolmitriptan to improve the bioavailability of the drug.

Methods: Liquisolid ODTs of zolmitriptan were prepared from; microcrystalline cellulose (Avicel PH-102) as carrier, colloidal silicon dioxide (Aerosil 200) as a coating material, croscarmellose sodium (CSS), sodium starch glycolate (SSG), and crospovidone (CP) as super disintegrants, and propylene glycol as liquid vehicle. The ratio of carrier to coating material was kept constant in all formulations at 35:1, this ratio was chosen after testing the ratios 10:1, 15:1, 20:1, 25:1,30:1, and 35:1. The ratio 35:1 give optimal results relative to other ratios. The pre-compression evaluation includes: flow properties were measured using the angle of repose and the compressibility index and FT-IR. The prepared liquid-solid system compacts were evaluated for their post-compression evaluation which includes: hardness, friability, wetting time, in vitro disintegration time, drug content and in vitro drug release.
\end{abstract}

Results: The tabletting properties of the liquid-solid ODTs were within the acceptable limits. Among the three super disintegrants, CP found to be the best in term of showing the fastest disintegration time. The optimized selected formula (F11) was prepared using $5 \% \mathrm{w} / \mathrm{w}$ crospovidone, by direct compression showed the shortest disintegration time $(24 \mathrm{~s}$ ), superior drug release profile [ the time required for $80 \%$ of the drug to be released $\left(\mathrm{T}_{80} \%\right)$ and percent drug dissolved in $2 \mathrm{~min}\left(\mathrm{D}_{2} \mathrm{~min}\right) 1.84 \mathrm{~min}$ and $87.59 \%$, respectively]. In addition to that, the selected formula had an acceptable hardness and friability, so it was selected as the best formula.

Conclusion: The overall results showed that CP was the best super disintegrant of showing the shortest disintegration time while loading factor of 0.125 was the best in the preparing of zolmitriptan liquid-solid ODTs, and this suggested the possibility of utilizing the selected best formula (F11) in the preparation of zolmitriptan ODTs as a new dosage form for oral administration.

Keywords: Orodispersible tablet, Zolmitriptan, Liquisolid technique

(C) 2017 The Authors. Published by Innovare Academic Sciences Pvt Ltd. This is an open access article under the CC BY license (http://creativecommons.org/licenses/by/4. 0/) DOI: http://dx.doi.org/10.22159/ijpps.2017v9i1.15656

\section{INTRODUCTION}

Many newly developed drugs are poorly water soluble compounds, which lead to problems in the development of dosage forms with sufficient bioavailability [1]. Solubility is the most important parameter to achieve the desired concentration of the drug in the systemic circulation for therapeutic response to be shown [2]. The majority of the hydrophobic drugs are sparingly soluble, slightly soluble, very slightly soluble and practically insoluble drugs. For each drug substances mentioned above, the dissolution is the rate-limiting step; so, the challenges for absorption of poorly water-soluble drugs are to improve the dissolution rate. This lead to enhancement of the absorption and bioavailability of these drugs [3].

The term liquid-solid systems refer to the powdered forms of liquid drugs formulated by changing liquid lipophilic drugs, drug suspensions or solutions of water-insoluble solid drugs in suitable non-volatile vehicle systems into dry, non-adherent, freely flowing and readily compressible powder mixtures by simple mixing with selected powder excipients known as the carrier and coating materials. Generally, microcrystalline cellulose (Avicel ${ }^{\circledR}$ ) is utilised as the carrier material and amorphous silicon dioxide (colloidal silica) as a coating material [4].

Many patient groups like elderly, children and mentally retarded patients who are uncooperative, nauseated or on decreased liquid intake/diets have difficulties in swallowing the solid dosage forms. Those who are travelling or have little water access are evenly affected [5]. To accomplish these medical needs, pharmaceutical technologists have developed a patient-friendly novel oral dosage form known as "Orally Disintegrating Tablets" which disintegrate rapidly in saliva, usually within seconds, without needing for water.
Drug dissolution, absorption, the onset of therapeutic effect and drug bioavailability may be significantly better than those obtained from conventional dosage forms [6].

Zolmitriptan (4S)-4-[[3-[2-dimethylamino ethyl]-1Hindol-5-yl] methyl] oxazolidinone, is a white to almost white powder, slightly soluble in water. It has a pKa value of 9.6. The bioavailability of zolmitriptan is about $40 \%$ from oral and nasal dosage forms and problem arises from its low water solubility and dissolution rate. Zolmitriptan used for patients with migraine attacks, with or without an aura, and cluster headaches. It acts selectively on serotonin (5-HT1B/1D) receptors. It is presently available as a conventional tablet, an oral disintegrating tablet and a nasal spray ( $2.5 \mathrm{mg}$ and $5 \mathrm{mg}$ per dose) [7, 8]. Patients with a migraine generally suffer from nausea and vomiting. Furthermore, in migraine attack there is delayed gastric emptying with a resulting delayed absorption during attacks; therefore, oral treatment could be inconvenient or could fail. Therefore, zolmitriptan given as ODT might provide rapid-acting, non-invasive delivery system for anti-migraine drugs to enhance patient compliance [9]. The aim behind this study is to prepare and evaluate zolmitriptan as an ODTs by liquid solid systems technique to enhance the disintegration and dissolution of zolmitriptan to improve the bioavailability of the drug.

\section{MATERIALS AND METHODS}

\section{Materials}

Zolmitriptan, microcrystalline cellulose (Avicel PH-102), silicon dioxide (Aerosil 200), croscarmellose sodium, crospovidone, sodium starch glycolate are obtained by Hangzhou Hyper Chemicals Limited, China. Propylene glycol (PG) was purchased from Fluka Chemi AG, 
Switzerland. Sodium saccharin, vanillin, disodium hydrogen orthophosphate and potassium dihydrogen orthophosphate were purchased from BDH chemical LTD, UK.

\section{Methods}

\section{Solubility studies}

Solubility studies of zolmitriptan were carried out in PG, PEG 400 and tween 80 to select the best non-volatile solvent for the dissolving of zolmitriptan in a liquid vehicle. Also simulated gastric fluid (SGF), $\mathrm{pH}$ 1.2 and simulated intestinal fluid (SIF), pH 6.8 were utilised to study solubility behaviour of zolmitriptan. Saturated solutions were prepared by adding much of zolmitriptan to the vehicles and shaking with the shaker for $48 \mathrm{~h}$ with a constant vibration. Then the solutions were filtered through a $0.45 \mathrm{~mm}$ millipore filter, diluted and analysed by UV-spectrophotometer. The sample was analysed in triplicate to calculate the solubility of zolmitriptan [10].

\section{Use of a mathematical model to design solid-liquid systems}

The flowability and compressibility of liquid solid compacts are addressed simultaneously in the new formulation mathematical model of liquid solid systems, which was used to calculate the appropriate quantities of the carrier and coating materials required to produce acceptably flowing and compressible powders based on new fundamental powder properties called the flowable liquid retention potential ( $\Phi$-value) and compressible liquid retention potential ( $\Psi$-number) of the constituent powders. The flowable liquid retention potential of powder is defined as the maximum amount of a given non-volatile liquid that can be retained inside its bulk (w/w) while maintaining acceptable flowability [11].

The compressible liquid retention potential $(\Psi)$ of powder is the maximum amount of liquid; the powder can retain inside its bulk (w/w) while maintaining acceptable compact ability, to produce compacts of suitable hardness and friability, with no liquid squeezing out phenomenon during the compression process. The $\Phi$ value of powders may be determined using a new procedure, the liquid solid flowability (LSF) test. The $\Psi$ number of powders may be determined using a new method termed the liquid solid compressibility (LSC) test which employs the 'pactisity theories' to evaluate the compaction properties of liquid/powder admixtures. According to the new theories, the carrier and coating powder materials can retain only certain amounts of liquid while maintaining acceptable flow and compression properties [12]. Depending on the excipients ratio $(\mathrm{R})$ or the carrier: coating ratio of the powder system used, where,

$$
\mathrm{R}=\mathrm{Q} / \mathrm{q} \ldots \ldots . . .(1)
$$

As $\mathrm{R}$ represents the ratio between the weights of carrier $(\mathrm{Q})$ and coating (q) materials present in the formulation. An acceptably flowing and compressible liquisolid system can be prepared only if a maximum liquid on the carrier material is not exceeded; such a characteristic amount of liquid is termed the liquid load factor (Lf) and defined as the ratio of the weight of liquid medication (W) over the weight of the carrier powder (Q) in the system, which should be possessed by an acceptably flowing and compressible liquid solid system. i.e.

$$
\mathrm{Lf}=\mathrm{W} / \mathrm{Q} \ldots \ldots \ldots(2)
$$

The powder excipients ratios $\mathrm{R}$ and liquid load factors Lf of the formulations is related as follows:

$$
\Psi \mathrm{Lf}=\Phi+\Phi(1 / \mathrm{R})
$$

In order to calculate the required ingredient quantities, the flowable liquid retention potentials ( $\Phi$-values) of powder excipients were utilised. So to calculate the required weights of the excipients used, first, from Eq. (3), $\Phi$ and $\Phi$ and are constants, therefore, according to the ratio of the carrier/coat materials (R), Lf was calculated from the linear relationship of Lf versus $1 / R$. Next, according to the used liquid vehicle concentration, different weights of the liquid drug solution (W) will be used. So, by knowing both Lf and W, the appropriate quantities of the carrier (Q) and coating (q) powder materials required to convert a given amount of liquid medication (W) into an acceptably flowing and compressible liquid solid system could be calculated from equations (1) and (2).

\section{Formulation of liquid solid ODTs of zolmitriptan}

Various liquid solid ODTs formulas denoted (F1 to F11) as shown in table (1) containing $2.5 \mathrm{mg}$ of zolmitriptan were prepared by dispersing the drug in the non-volatile vehicle (PG). Then a bindery mixture of carrier of carrier (Avicel PH 102) and coating material (Aerosil 200) was prepared at a ratio of 35: 1 (trial and error methods were used, i.e. changing the carrier: coating material ratio (R) from $10,15,20,25,30$, and 35:1 until get good result (flow properties) is obtained. R 35 was used in all formulations since it gave the optimal flow property. This binary mixture was added to the admixture of drug and vehicle. Finally, super disintegrant and other excipients were added to the above powder blend and mixed thoroughly. The final powder blend was subjected to direct compression [13]. The formulas F1-F9 were prepared using different types and concentrations $(2.5 \%, 5 \%$, and $7.5 \%)$ of super disintegrants namely CSS, SSG, and CP. The loading factor was kept constant in the above formulas which equal to 0.25 ; this loading factor was decreased to $50 \%$ from its original value in formula F10 to become 0.175 , while in formula F11, the loading factor 0.25 was decreased to

\begin{tabular}{|c|c|c|c|c|c|c|c|c|c|}
\hline $\begin{array}{l}\text { Formula } \\
\text { Code* }\end{array}$ & $\begin{array}{l}\text { CSS } \\
(\mathrm{mg})\end{array}$ & $\begin{array}{l}\text { SSG } \\
\text { (mg) }\end{array}$ & $\begin{array}{l}\mathrm{CP} \\
\text { (mg) }\end{array}$ & $\begin{array}{l}\text { Avicel PH-102 } \\
\text { (mg) }\end{array}$ & $\begin{array}{l}\text { Aerosil } \\
200(\mathrm{mg})\end{array}$ & $\begin{array}{l}\text { Na sacchar- } \\
\text { in } 1 \%(\mathrm{mg})\end{array}$ & $\begin{array}{l}\text { Vanillin } \\
1 \%(\mathrm{mg})\end{array}$ & $\begin{array}{l}\text { Mg stearate } \\
1 \% \text { (mg) }\end{array}$ & $\begin{array}{l}\text { Total weight } \\
\text { (mg) }\end{array}$ \\
\hline F1 & $\begin{array}{l}3.5 \\
(2.5 \%)\end{array}$ & & & 104.5 & 2.8 & 1.4 & 1.4 & 1.4 & 140 \\
\hline F2 & $7(5 \%)$ & & & 101 & 2.8 & 1.4 & 1.4 & 1.4 & 140 \\
\hline F3 & $\begin{array}{l}10.5 \\
(7.5 \%)\end{array}$ & & & 97.5 & 2.8 & 1.4 & 1.4 & 1.4 & 140 \\
\hline F4 & & $\begin{array}{l}3.5 \\
(2.5 \%)\end{array}$ & & 104.5 & 2.8 & 1.4 & 1.4 & 1.4 & 140 \\
\hline F5 & & $7(5 \%)$ & & 101 & 2.8 & 1.4 & 1.4 & 1.4 & 140 \\
\hline F6 & & $\begin{array}{l}10.5 \\
(7.5 \%)\end{array}$ & & 97.5 & 2.8 & 1.4 & 1.4 & 1.4 & 140 \\
\hline F7 & & & $\begin{array}{l}3.5 \\
(2.5 \%)\end{array}$ & 104.5 & 2.8 & 1.4 & 1.4 & 1.4 & 140 \\
\hline F8 & & & $\begin{array}{l}7 \\
(5 \%)\end{array}$ & 101 & 2.8 & 1.4 & 1.4 & 1.4 & 140 \\
\hline F9 & & & $\begin{array}{l}10.5 \\
(7.5 \%)\end{array}$ & 97.5 & 2.8 & 1.4 & 1.4 & 1.4 & 140 \\
\hline F10 & & & $\begin{array}{l}9.3 \\
(5 \%)\end{array}$ & 142.1 & 4 & 1.86 & 1.86 & 1.86 & 186 \\
\hline F11 & & & $\begin{array}{l}12.5 \\
(5 \%)\end{array}$ & 199.5 & 5.5 & 2.5 & 2.5 & 2.5 & 250 \\
\hline DCT & & & $\begin{array}{l}12.5 \\
(5 \%)\end{array}$ & 221.2 & 6.31 & 2.5 & 2.5 & 2.5 & 250 \\
\hline
\end{tabular}
$100 \%$ to become 0.125

Table 1: Composition of different zolmitriptan liquid solid ODTs formulas

*Each formula contains $2.5 \mathrm{mg}$ zolmitriptan 


\section{Preparation of directly compressible ODTs (DCT) of zolmitriptan}

Directly compressible ODTs (DCT) of zolmitriptan were prepared by direct compression using single tablet punch machine, each containing $2.5 \mathrm{mg}$ zolmitriptan, $221.2 \mathrm{mg}$ Avicel PH 102, $6.31 \mathrm{mg}$ Aerosil 200 (ratio of Avicel PH-102 to Aerosil 200 was set at 35:1), 5 $\% \mathrm{w} / \mathrm{w} \mathrm{CP}$ as super disintegrant, and $1 \% \mathrm{w} / \mathrm{w}$ of magnesium stearate, sodium saccharin, and vanillin, respectively. These tablets were prepared by mixing the drug with Avicel PH-102 and Aerosil 200 for a period of $10 \mathrm{~min}$. The blend was mixed with CP and other additives for $10 \mathrm{~min}$ then magnesium stearate was added and mixed for $2 \mathrm{~min}$. After that, the final mixture was directly compressed using a single punch tabletting machine $8 \mathrm{~mm}$ die size [14].

\section{Pre-compression evaluation of zolmitriptan liquid solid ODTs}

The flow properties of the liquid, solid systems were of critical importance in the production of pharmaceutical dosage forms in order to get a uniform feed, as well as the reproducible filling of tablet, dies otherwise high dose weight variations will occur. The flow properties of the liquid solid powders were estimated by determining the angle of repose and Carr's index. The angle of repose was measured by the fixed funnel method. The bulk density and tap density were determined for the calculation of Carr's index [15, 16].

\section{Post-compression evaluation of zolmitriptan liquid solid ODTs}

\section{Hardness test}

A hardness tester apparatus (Monsanto) was used to determine the tablet hardness. Three tablets were randomly selected from each batch of ODTs tablets for determination of hardness. The mean of three determinations \pm SD was recorded. The hardness was expressed as a force in $\mathrm{kg} / \mathrm{cm}^{2}$ required to crush the tablets [17].

\section{Friability test}

Friability test was performed to evaluate the effect of friction and shocks, which may often cause tablets to chip, cap or break. Roche friabilator apparatus was used for this purpose. It is expressed as a percentage (\%) Ten tablets were initially weighed (W initial) and put in the friabilator. The friabilator was operated at up to 100 revolutions. The tablets were weighed again (W final). The percentage friability was then calculated using the following equation:

$\%$ Friability $=(\mathrm{W}$ initial- $\mathrm{W}$ final $) / \mathrm{W}$ initial $\times 100 \%$.

\section{Content uniformity test}

Ten tablets from each batch were grounded in a mortar to a fine powder then powder mass equivalent to $2.5 \mathrm{mg}$ of zolmitriptan was transferred into $100 \mathrm{ml}$ volumetric flask, then the volume was completed to $100 \mathrm{ml}$ with phosphate buffer ( $\mathrm{pH}$ 6.8). The solution was sonicated and shaken intermittently for $1 \mathrm{~h}$ sonication and filtered. After the desired dilution, the solution was analysed for drug content at $\lambda$ max $222 \mathrm{~nm}$ with a UV-Visible spectrophotometer using phosphate buffer ( $\mathrm{pH}$ 6.8) as blank [19].

\section{Wetting time test}

The wetting time of tablets was measured using a simple procedure. A piece of sponge $(0.5 \mathrm{~cm}$ thickness) was placed in a small Petri dish (internal diameter $=12 \mathrm{~cm}$ ) containing $10 \mathrm{ml}$ of artificial saliva containing methylene blue (a water soluble dye). The dye solution is utilized to recognize the complete wetting of the tablet surface. The method was performed by maintaining artificial saliva at $37^{\circ} \mathrm{C}$. A tablet was placed on the sponge surface carefully and the time required for the complete wetting of the tablet was recorded as a wetting time as shown in fig. (1). The mean of three determinations was used \pm SD. The artificial saliva used was composed of $\mathrm{NaCl}(8 \mathrm{~g} / \mathrm{l}), \mathrm{KH}_{2} \mathrm{PO}_{4}(0.19 \mathrm{~g} / \mathrm{l})$ and $\mathrm{Na}_{2} \mathrm{HPO}_{4}(2.38 \mathrm{~g} / \mathrm{l})[20]$.
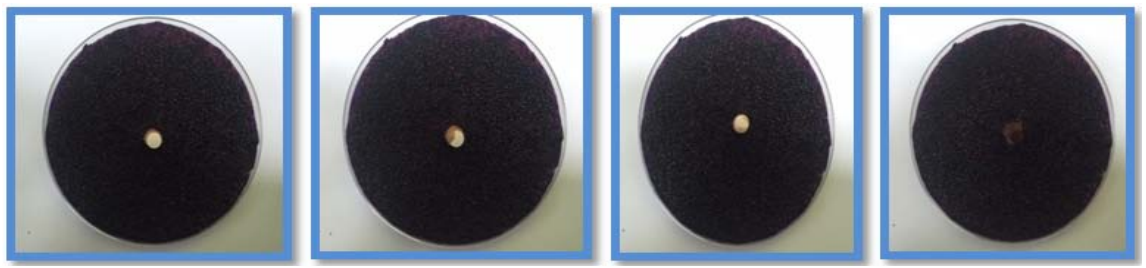

Fig. 1: Wetting time test performed on the prepared ODTs of zolmitriptan

\section{In vitro disintegration time test}

One of the most important characteristics of the ODT is the disintegration time in the oral cavity; yet, the disintegration time of ODTs is measured using the conventional tests (for tablets) that were described in the Pharmacopoeias. However, it is hard to determine the disintegration time for the ODT with these tests due to its rapid disintegration rate even in a small amount of water. Further, the conventional tests use a volume of $800-900 \mathrm{ml}$ of the test solution compared to the volume of saliva in humans, which is less than $6 \mathrm{ml}$. Thus, the disintegration time obtained from the conventional disintegration tests show not to be reflective of the disintegration time in the human mouth. To overcome this problem, A new modified apparatus represented as a suitable method to determine the disintegration time of ODTs was developed. A modified apparatus fig. (2) Consisting of a glass beaker of $10 \mathrm{ml}$ capacity contained $6 \mathrm{ml}$ of salivary phosphate buffer $\mathrm{pH} 6.8$ as a disintegration medium was placed on the magnetic stirrer. A very small magnetic bead was put at the bottom of a beaker and temperature was maintained at $37 \pm 2{ }^{\circ} \mathrm{C}$. Disintegration time was determined at $50 \mathrm{rpm}$. The disintegration test was performed on six tablets $[21,22]$.
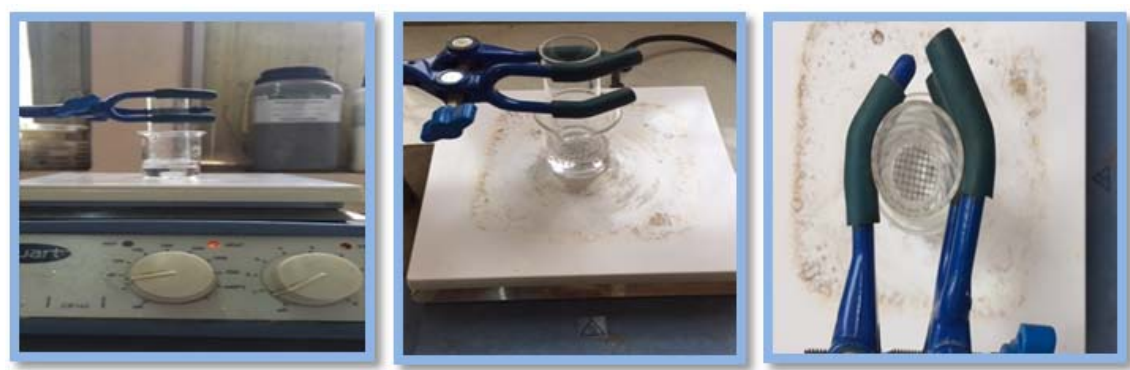

Fig. 2: Modified disintegration test apparatus used to determine the disintegration time of the prepared ODTs of zolmitriptan 


\section{In vitro dissolution studies of zolmitriptan liquisolid ODTs}

The release profile of selected formula of zolmitriptan liquisolid orodispersible tablets was performed in $500 \mathrm{ml}$ phosphate buffer $\mathrm{pH}$ 6.8 maintained at $37 \pm 0.5{ }^{\circ} \mathrm{C}$ using the USP Dissolution Tester Apparatus II, at a rotation speed of $50 \mathrm{rpm}$. Also, dissolution study was performed for DCT. Aliquots from the dissolution medium (5 $\mathrm{ml}$ ) were withdrawn at $1,2,3,4,5,6,7,8,9,10,12.5,15,20,25$ and 30 min time intervals. The samples were replaced with fresh dissolution medium of same quantity in order to maintain the volume in the vessels constant. Samples were filtered using 0.45 millipore filter and drug content was determined spectrophotometrically at $\lambda$ max $222 \mathrm{~nm}$. The percentage of drug dissolved in $2 \min \left(D_{2} \min \right)$ and the time required for $80 \%$ of drug to be released $\left(\mathrm{T}_{80 \%}\right)$ were considered for comparing the dissolution results for the prepared zolmitriptan liquisolid ODTs formula and DCT. Each preparation was tested in triplicate and the mean value was calculated [23].

\section{Fourier transform infrared spectroscopy (FT-IR)}

This study was achieved to identify any sign of complexation and interaction between zolmitriptan and other excipients used in the preparation of zolmitriptan liquisolid ODTs. The samples are grinded and mixed with potassium bromide. The spectrum was obtained between the wave number of $4000-400 \mathrm{~cm}^{-1}$

\section{Accelerated stability study (effect of humidity)}

The stability study was done for the best formula. The tablets were stored at $40{ }^{\circ} \mathrm{C} / 75 \pm 5 \% \mathrm{RH}$ using stability chamber for the duration of four months. After an interval of four months, samples were withdrawn and tested for various physical tests (wetting time, hardness, friability, disintegration time and uniformity of dosage unit tests) and drug release study [24].

\section{Statistical analysis}

The results of the experiments were presented as a mean of triplicate samples \pm standard deviation and analyzed by one-way analysis of variance (ANOVA) at the level of $(\mathrm{P}<0.05)$.

\section{RESULTS AND DISCUSSION}

The solubility of zolmitriptan in various solvents is given in table (2). The table shows that the solubility of zolmitriptan was increased with decreasing $\mathrm{pH}$; this is because that zolmitriptan is a basic drug with a pK of 9.6 (i. e zolmitriptan become ionised by decreasing $\mathrm{pH}$ ). The table shows that the solubility of zolmitriptan was markedly ( $\mathrm{P}$ $<0.05$ ) increased in the presence of PG, because PG (an alcoholic compound) might exhibit hydrogen bonding due to the presence of hydroxyl groups, furthermore, PG has a low viscosity ( $48 \mathrm{mPa}$ ) and molecular weight $(76.1 \mathrm{~g} / \mathrm{mol})$, compared to tween 80 that has high viscosity (425 $\mathrm{mPa} \mathrm{s}$ ) and molecular weight $(1310 \mathrm{~g} / \mathrm{mol})[25,26]$.

Table 2: Solubility of zolmitriptan in various solvents

\begin{tabular}{ll}
\hline Solvents & Solubility (\% w/w) mean \pm SD* \\
\hline Distilled water & $0.122 \pm 0.0546$ \\
(0.1 N HCl) & $1.873 \pm 0.1162$ \\
(phosphate buffer pH 6.8) & $0.235 \pm 0.0972$ \\
PG & $7.721 \pm 0.6553$ \\
PEG 400 & $0.737 \pm 0.0475$ \\
Tween 80 & $0.132 \pm 0.0126$ \\
\hline
\end{tabular}

*SD standard deviation from mean. $\mathrm{n}=3$

\section{Application of new mathematical model for design of liquisolid systems}

In order to calculate the required ingredient quantities, the flowable liquid retention potentials ( $\Phi$-values) of powder excipients were utilised. The values of the flowable liquid retention potentials for Avicel PH-102 and Aerosil 200 in PG were (0.16) and (3.33), respectively $[11,12]$. The loading factor (Lf) was calculated from the following equation:

$$
\mathrm{Lf}=0.16+3.33(1 / 35) \text { for } \mathrm{PG} \text {........ (7) }
$$

The optimal R-value was 35:1, the corresponding optimal liquid load factor of a given excipients ratio was established. The appropriate quantities of Avicel PH 102 (Q) and Aerosil 200 (q) required to convert a given amount of liquid medication (W) into an acceptably flowing and compressible liquisolid system, were calculated using Eqs. (1) and (2). and it was equal to 0.25 . A reasonable flow was achieved when the liquid loading factors (Lf) equal to or lower than 0.25 , this is in agreement with what was stated in literature that it is hard to prepare formulation with good flowability and compactibility when loading factor is above 0.25 , because fewer amounts of carrier and coating materials are used during preparation of these formulations, and excess liquid is not completely absorbed, leading to the formation of agglomerates [27].

Pre-compression studies of the prepared liquisolid orodispersible powder system

The data obtained for pre-compression parameters for formulas F1F11 and DCT such as carr's index and angle of repose are shown in table (3) and was within acceptable limits according to USP [28].

Table 3: Angle of repose and carr's index of powder formulas according to USP

\begin{tabular}{|c|c|c|c|}
\hline Formula no. & Angle of repose* & Carr's index* & Flow-compression character \\
\hline 1 & $33.4 \pm 0.22$ & $19.6 \pm 0.47$ & Good to fair \\
\hline 2 & $34.6 \pm 1.78$ & $18.4 \pm 0.79$ & Good to fair \\
\hline 3 & $34.7 \pm 1.94$ & $19.4 \pm 0.85$ & Good to fair \\
\hline 4 & $33.6 \pm 0.70$ & $18.8 \pm 1.62$ & Good to fair \\
\hline 5 & $33.1 \pm 2.06$ & $16.7 \pm 1.42$ & Good to fair \\
\hline 6 & $32.3 \pm 0.55$ & $16.6 \pm 2.12$ & Good to fair \\
\hline 7 & $30.0 \pm 0.69$ & $15.7 \pm 2.39$ & Excellent to Good \\
\hline 8 & $30.1 \pm 0.65$ & $14.3 \pm 0.56$ & Excellent to Good \\
\hline 9 & $29.7 \pm 0.47$ & $12.6 \pm 0.91$ & Excellent to Good \\
\hline 10 & $27.5 \pm 0.87$ & $14.3 \pm 0.94$ & Excellent to Good \\
\hline 11 & $25.1 \pm 1.80$ & $15.1 \pm 0.91$ & Excellent to Good \\
\hline DCT & $32.4 \pm 0.57$ & $19.2 \pm 0.219$ & Good to Fair \\
\hline
\end{tabular}

*SD standard deviation from mean. $\mathrm{n}=3$. 
Post-compression evaluation of zolmitriptan liquisolid ODTs: hardness, friability, and content uniformity

Post-compression parameters like hardness, friability and content uniformity were mentioned in table (4). The tablets measured hardness was found to be in the range of 3.03 to $4.75 \mathrm{~kg} / \mathrm{cm}^{2}$. The percentage of friability was less than $1 \%$ for all formulations ensuring the optimum mechanical stability of the formulated tablets. The percentage of the drug content for the all formulas was found in the range of $97.4-100.6 \%$ which comply with the USP limits [28].

Table 4: Hardness, friability, content uniformity percentage, wetting time and disintegration time of zolmitriptan liquisolid orodispersible tablets

\begin{tabular}{|c|c|c|c|c|c|}
\hline $\begin{array}{l}\text { Formula } \\
\text { code }\end{array}$ & $\begin{array}{l}\text { Hardness } \mathrm{kg} / \mathrm{cm}^{2} \\
\text { mean } \pm S D, n=3\end{array}$ & $\begin{array}{l}\% \text { Friability }(w / w) \\
\text { Mean, } n=10\end{array}$ & $\begin{array}{l}\% \text { content uniformity } \\
\text { mean } \pm S D, n=10\end{array}$ & $\begin{array}{l}\text { Wetting time } \\
\text { Mean (s) } \pm S D, n=3\end{array}$ & $\begin{array}{l}\text { Disintegration time } \\
\text { mean }(s) \pm S D, n=6\end{array}$ \\
\hline F1 & $4.20 \pm 0.20$ & 0.72 & $99.4 \pm 2.07$ & $288 \pm 7.45$ & $185 \pm 9.87$ \\
\hline F2 & $4.13 \pm 0.05$ & 0.86 & $98.6 \pm 3.20$ & $253 \pm 5.54$ & $201 \pm 7.52$ \\
\hline F3 & $3.90 \pm 0.26$ & 0.46 & $99.6 \pm 4.15$ & $217 \pm 8.61$ & $221 \pm 7.78$ \\
\hline F4 & $3.70 \pm 0.17$ & 0.40 & $100.2 \pm 2.16$ & $246 \pm 7.57$ & $126 \pm 5.62$ \\
\hline F5 & $3.36 \pm 0.11$ & 0.89 & $97.8 \pm 2.68$ & $207 \pm 5.72$ & $101 \pm 3.09$ \\
\hline F6 & $3.03 \pm 0.15$ & 0.73 & $100.6 \pm 2.70$ & $167 \pm 9.45$ & $118 \pm 5.33$ \\
\hline F7 & $4.00 \pm 0.00$ & 0.21 & $97.4 \pm 3.50$ & $76 \pm 3.31$ & $79 \pm 2.40$ \\
\hline F8 & $4.23 \pm 0.20$ & 0.75 & $100.8 \pm 0.83$ & $68 \pm 3.12$ & $48 \pm 1.63$ \\
\hline F9 & $4.75 \pm 0.25$ & 0.28 & $99.8 \pm 3.91$ & $53 \pm 5.34$ & $61 \pm 3.73$ \\
\hline F10 & $4.10 \pm 0.42$ & 0.70 & $98.8 \pm 2.38$ & $54 \pm 2.74$ & $33 \pm 2.43$ \\
\hline F11 & $4.11 \pm 0.39$ & 0.35 & $100.2 \pm 1.30$ & $40 \pm 1.41$ & $24 \pm 1.53$ \\
\hline DCT & $4.29 \pm 0.29$ & 0.66 & $100.2 \pm 2.23$ & $71 \pm 2.37$ & $44 \pm 3.17$ \\
\hline
\end{tabular}

\section{Wetting time (WT) and In vitro disintegration time (DT)}

The wetting and disintegration behaviour of the prepared zolmitriptan liquisolid ODTs in salivary phosphate buffer $\mathrm{pH} 6.8$ were shown in the table (4). It was observed that the WT and DT for F1-F9 formulas were influenced by the type and concentration of super disintegrant. Table (4) shows that the best super disintegrant type was CP among the other super disintegrants CSS and SSG, this is due to the fact that $\mathrm{CP}$ rapidly wicks water into the tablet to create the volume expansion and hydrostatic pressure required to provide rapid disintegration. The results are in agreement with those reported in the literature [29]. Concerning the concentration of the super disintegrant, a rational concentration should be utilized in the formulation of ODTs, because increasing the concentration over an optimum one lead to an increase in the DT of the tablet. From data in table (4), as the concentration of the super disintegrant increase, the DT consistently increase. This increase in DT was more marked in formulas F3, F6 and less in F9. The reason behind this increase may be due to the formation of viscous gel layer on the surface of the tablet which prevents the penetration of water to the core of the tablet especially for super disintegrant CSS and SSG [30], as shown in fig. (3). More gel was formed with CCS than with SSG. This makes DT of tablets with super disintegrant CCS more than that of tablets with SSG (DT of tablets prepared with CCS 7.5\% (F3) and SSG 7.5\% (F6) were 221 and $118 \mathrm{~s}$, respectively). In contrast, CP has less tendency to gelling [29]. In F9 which contains 7.5\% CP there is a slight increase in DT, because the quick expansion of the largest capillaries isolates other areas of fine pores structure in which air cannot escape. These areas make no role to the overall uptake of liquid [31]. Moreover, it can be concluded that as the concentration of the super disintegrant increase, the WT decrease.

The formulas F10 and F11 were prepared with the loading factors 0.175 and 0.125 , respectively; and their WT and DT were compared to the formula F8 with a loading factor of 0.25 . From the results shown in table (4), a significant $(\mathrm{p}<0.05)$ decrease in the WT and DT was seen as the loading factor was decreased. This is due to that as the loading factor decrease, the amount of Avicel PH-102 will increase according to the equation $\mathrm{Lf}=\mathrm{W} / \mathrm{Q}$, where $\mathrm{Q}$ is the weight of Avicel PH-102. Microcrystalline cellulose (Avicel PH-102) has a very high intraparticle porosity. This high porosity support is swelling and disintegration of ODTs, due to the penetration of water into the hydrophilic tablet matrix by capillary action which generates pressure for fast and complete disintegration of the tablets. So, microcrystalline cellulose acts as auxiliary tablet disintegrant because of its high water absorption capacity [32].

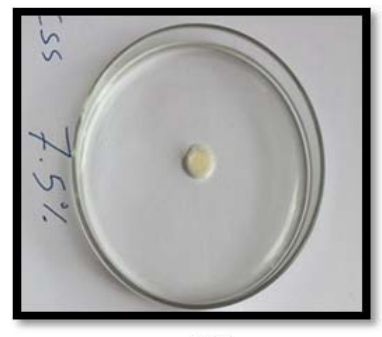

(A)

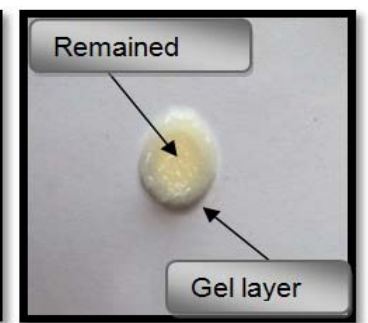

(B)

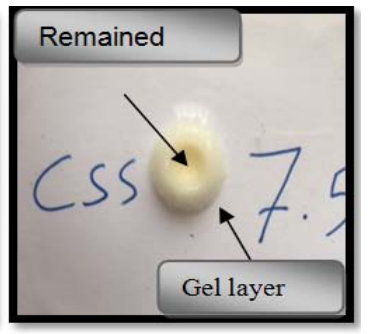

(C)

Fig. 3: The process of disintegration time test for F3 with 7.5\% CSS as super disintegrant: (A) beginning (B) at 30th s and (C) at 60th $s$

The disintegration time and wetting time of DCT orodispersible tablet of zolmitriptan were compared to F11. The results showed that F11 had significantly $(\mathrm{p}<0.05)$ lower WT and DT compared to DCT formula table (4). This is due to that solubilization of the drug in the nonvolatile liquid by liquisolid technique results in enhancing the wettability of the formulation (F11) compared to the DCT orodispersible tablet of zolmitriptan [33]. From the result shown in table (4), it can be concluded that formula F11 complies with USP specification of the disintegration time which is less than $30 \mathrm{~s}$ [28].

The liquisolid ODTs of zolmitriptan F11 was the best formula among all the formulas of the liquisolid ODTs tablets; in terms of rapid in vitro disintegration and acceptable tablet properties. The dissolution of the zolmitriptan from formula F11 was compared to the DCT of zolmitriptan as in fig. (4). From the data in table (5), it was found that F11 showed significant $(\mathrm{p}<0.05)$ faster dissolution compared to DCT of zolmitriptan, this attributed to the fact that zolmitriptan is already in solution form in PG, at the same time, it is hold by the powder particles (Avicel PH-102 and Aerosil 200). When the drug within the liquisolid system is completely dissolved in the liquid vehicle, it is located in the powder substrate still in a solubilized state. The accelerated release in zolmitriptan liquisolid ODTs (F11) is due to its markedly increased wettability and surface area available to the dissolution medium [34]. 


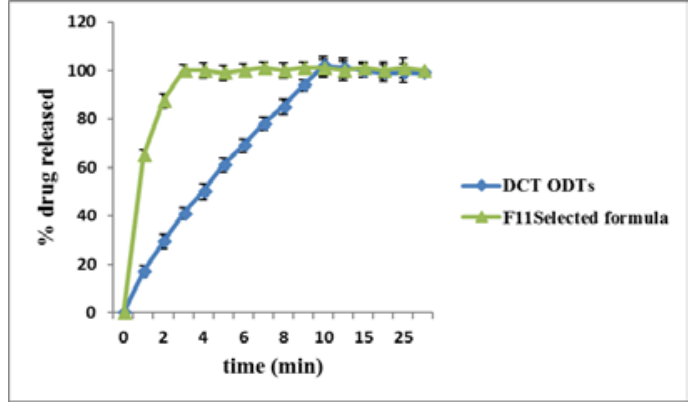

Fig. 4: A comparison in the dissolution profile of the prepared zolmitriptan liquisolid ODTs (F11) and DCT in phosphate buffer pH 6.8 at $37^{\circ} \mathrm{C}$. (Results are expressed as mean, $n=3$ )

Table 5: In vitro dissolution parameters of the liquisolid ODTs of zolmitriptan and DCT in phosphate buffer $\mathrm{pH} 6.8$ at $37^{\circ} \mathrm{C}$

\begin{tabular}{lll}
\hline Formula code & $\mathbf{D}_{\mathbf{2} \min }(\mathbf{\%})^{*}$ & $\mathbf{T}_{\mathbf{8 0} \%}(\mathbf{m i n})^{*}$ \\
\hline F11 & 87.59 & 1.84 \\
DCT & 29.41 & 7.52 \\
\hline
\end{tabular}

*Results are expressed as mean, $\mathrm{n}=3$ )

\section{Compatibility studies}

FT-IR of zolmitriptan showed three main characteristic absorption bands of strong absorbance at $1738 \mathrm{~cm}^{-1}$ due to $\mathrm{C}=0$ stretching vibrations of amino ester functional group OCONHR, N-H stretching band of secondary and tertiary amine appears at $3350 \mathrm{~cm}^{-1}$ as a single sharp band and C-O (stretching) of ester group at $1252 \mathrm{~cm}^{-1}[22]$ as in fig. (5). It was noted that the peaks of major functional groups of zolmitriptan, which are present in the spectrum of pure drug, were present in zolmitriptan liquisolid formula fig. (6) ( $\mathrm{C}=0$ stretching vibrations and C-O stretching of ester group except $\mathrm{N}-\mathrm{H}$ stretching of pure drug at $3350 \mathrm{~cm}^{-1}$ was overshadow with $\mathrm{OH}$ stretching of Avicel $\mathrm{PH}-102$ this due to the amount of the drug is too low compared to Avicel PH-102 (the ratio of the drug: Avicel PH-102 was 1:80 in the selected formula F18, also might be attributed to the formation of hydrogen bonding between the drug and liquid vehicle; this indicated lack the possibility of interaction between zolmitriptan and polymers used in the preparation of the liquisolid orodispersible tablets.

\section{Accelerated stability study (effect of humidity)}

Stability studies of the selected formula (F11) showed no significant difference $(p>0.05)$ in tablet hardness, $\%$ friability, drug content, disintegration time, wetting time and release profile after storage at $40 \pm 2{ }^{\circ} \mathrm{C} / 75 \pm 5 \% \mathrm{RH}$ for the duration of four months.

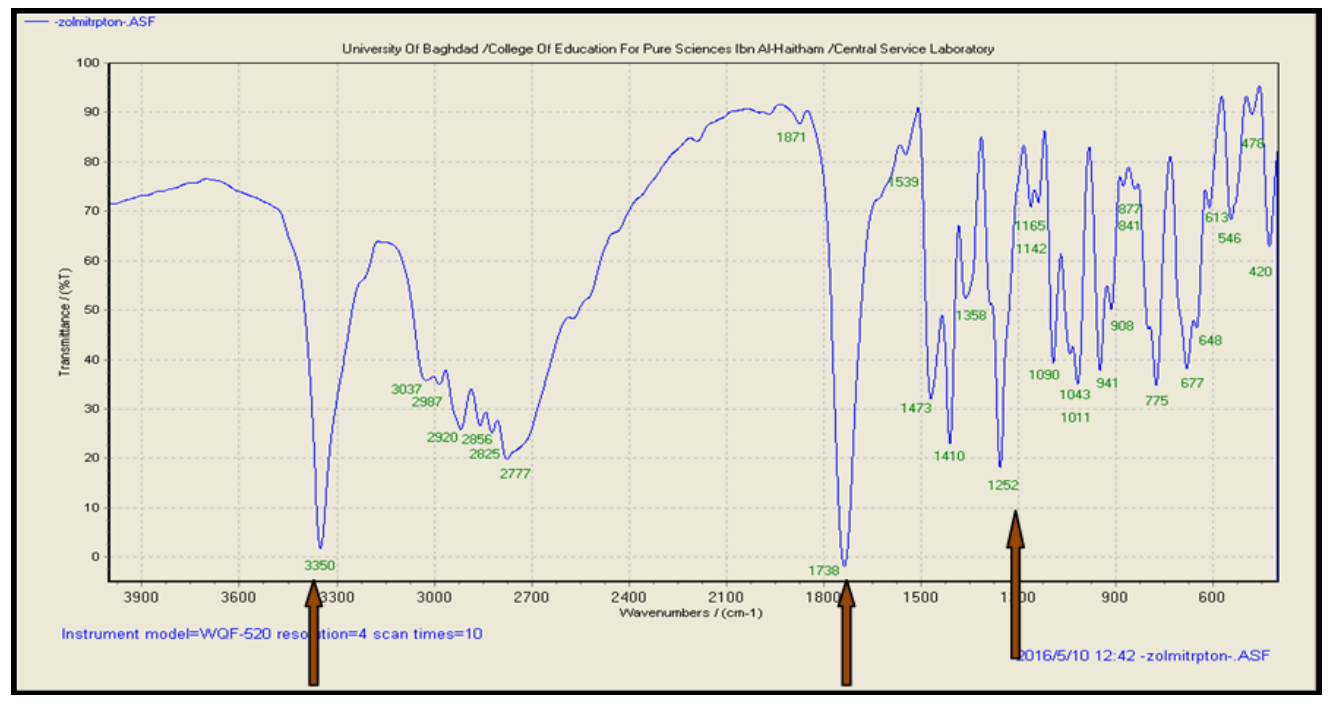

Fig. 5: FT-IR spectrum of pure zolmitriptan

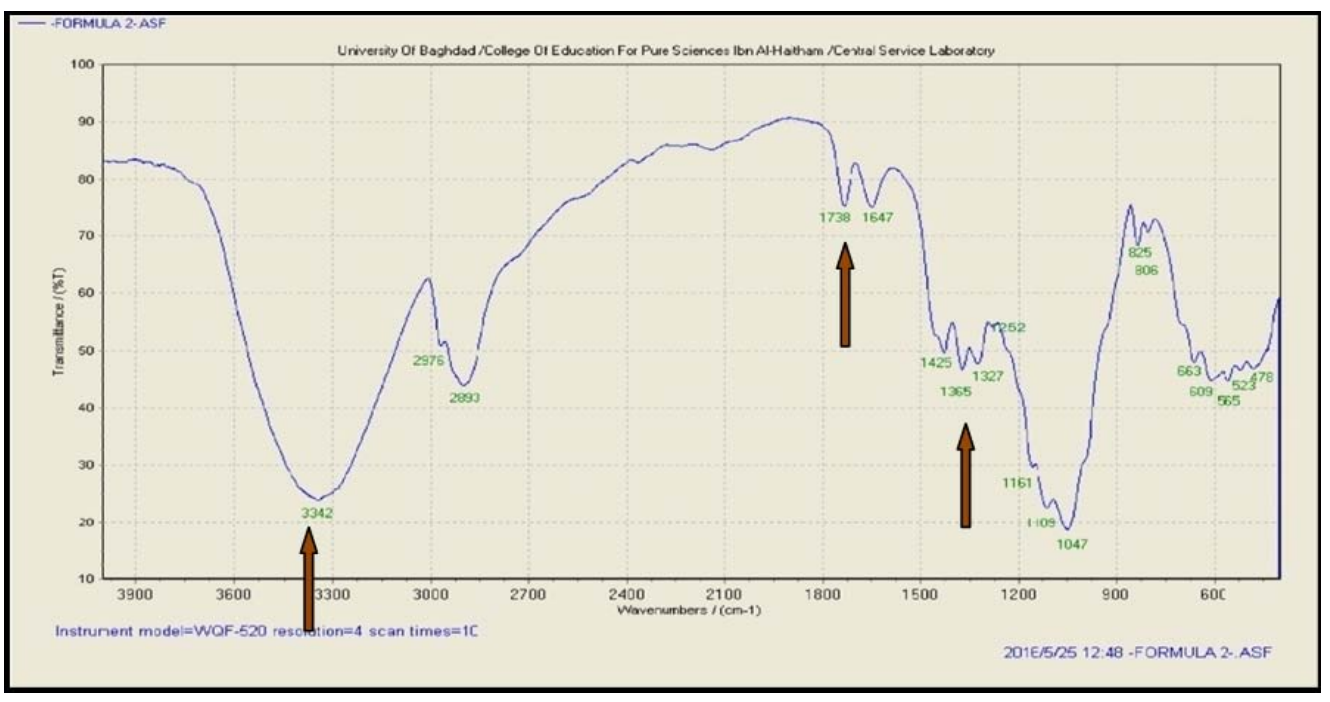

Fig. 6: FT-IR Spectrum of the liquisolid formula F11 


\section{CONCLUSION}

The orodispersible tablets of zolmitriptan were prepared by liquisolid technique method using different super disintegrants such as CP, SSG, and CSS. Among all super disintegrant, a formulation containing $\mathrm{CP}$ as a super disintegrant is fulfilling all the parameters satisfactorily compared to another super disintegrant. The relative efficiency of this super disintegrant to improve the disintegration time in order of $\mathrm{CP}>\mathrm{SSG}>\mathrm{CSS}$. In vitro release studies revealed that almost $95.2 \%$ drug was released from the formulation were within 2 min. The physicochemical properties and stability of the prepared liquisolid tablets were satisfactory. This study indicates the possibility of using the selected best formula (F11) in the preparation of zolmitriptan ODTs for oral administration because of desired properties of the prepared tablets concerning sufficient hardness, low friability, fast disintegration and dissolution.

\section{CONFLICT OF INTERESTS}

Declared none

\section{REFERENCES}

1. Dressman J, Reppas C. Drug solubility: how to measure it, how to improve it. Adv Drug Delivery Rev 2007;59:531-2.

2. Kumar VS, Raja C, Jayakumar C. A review on solubility enhancement using hydrotropic phenomena. Int J Pharm Pharm Sci 2014;6:1-7.

3. Khadka P, Ro J, Kim H, Kim I, Kim JT, Kim H, et al. Pharmaceutical particle technologies: An approach to improve drug solubility, dissolution, and bioavailability. Asian J Pharm Sci 2014;9:304-16.

4. Khan I, Khan ML, Khan U. Liquisolid technology: an emerging and advanced technique for enhancing solubilization. Pharm Tutor 2014;2:31-41.

5. Ganesh NS, Deshpande KB. Orodispersible tablets: an overview of formulation and technology. Int J Pharm Biol Sci 2011;2:726-34.

6. Paul Y, Tyagi S, Singh B. Formulation and evaluation of oral dispersible tablets of zidovudine with different super disintegrants. Int J Curr Pharm Rev Res 2011;2:81-91.

7. Patil PR, Salve VK, Thorat RU, Shahi SR. Formulation and evaluation of ion-sensitive in-situ nasal gel of zolmitriptan. Int J Pharm Pharm Sci 2015;7:478-86.

8. Bankim CN, Gupta AK, Mittal A, Mohd KZ. Design and development of solid dispersion system of zolmitriptan. J Biomed Pharm Res 2013;2:7-13.

9. Azza AM, Salwa S. Fast relief from migraine attacks using fastdisintegrating sublingual zolmitriptan tablets. Drug Dev Ind Pharm 2012;38:762-9.

10. Altememy DR, Altememy JJ. Formulation and evaluation of meloxicam liquisolid compact. Int J Pharm Pharm Sci 2014;6:453-63.

11. Spireas S, Bolton M. Liquisolid systems and methods of preparing same. US Patent 1999;5:968, 550.

12. Elkordy AA, Tan XN, Essa EA. Spironolactone release from liquisolid formulations prepared with Capryol $^{\mathrm{TM}}$ 90, Solutol $\AA$ HS-15 and Kollicoat ${ }^{\circledR}$ SR 30 D as non-volatile liquid vehicles. Eur J Pharm Biopharm 2013;83:203-23.

13. Karmarkar AB, Gonjari ID, Hosmani AH, Dhabale PN, Bhise SB. Dissolution rate enhancement of fenofibrate using liquisolid tablet technique. Lat Am J Pharm 2009;28:219-25.

14. MM Ghareeb, KK Atiya, JJ Ibraheem. Liquisolid compact as an approach for Tenoxicam solubility enhancement using tween 80 as liquid vehicle. J Chem Pharm Res 2015;7:379-93.

15. Kaerger S, Edge S, Price R. Influence of particle size and shape on flowability and compactibility of binary mixtures of paracetamol and microcrystalline cellulose. Eur J Pharm Sci 2004;22:173-9.
16. Parmar K, Patel J, Sheth N. Fabrication and characterization of liquisolid compacts of Embelin for dissolution enhancement. J Pharm Investig 2014;44:391-8.

17. Malke S, Shidhaye S, Kadam V. Novel melt granulation using sugars for metoclopramide hydrochloride orally disintegrating tablet. Asian J Pharm Clin Res 2009;2:68-72.

18. Ayalasomayajula LU. Formulation and evaluation of atenolol orodispersible tablets by co-processed super-disintegration process. Int J Adv Pharm 2016;5:46-51.

19. Bayrak Z, Tas C, Tasdemir U, Erol H, Ozkan CK, Savaser A, et al. Formulation of zolmitriptan sublingual tablets prepared by direct compression with different polymers: In vitro and in vivo evaluation. Eur J Pharm Biopharm 2011;78:499-505.

20. Patrick H, Jason L, Kenneth SA, Gabriella B. A new modified wetting test and an alternative disintegration test for orally disintegrating tablets. J Pharm Biomed Anal 2016;120:391-6.

21. Khan S, Kataria P, Nakhat P, Yeole P. Taste masking of ondansetron hydrochloride by polymer carrier system and formulation of rapid-disintegrating tablets. AAPS PharmSciTech 2007;8:127-33.

22. Brniak W, Jachowicz R, Pelka P. The practical approach to the evaluation of methods used to determine the disintegration time of orally disintegrating tablets (ODTs). Saudi Pharm J 2015;23:437-43.

23. Salim W, Khalil I. Formulation and evaluation of zolmitriptan bilayers oral strips. World J Pharm Res 2015;4:25-57.

24. Kopp S. Stability testing of pharmaceutical products in a global environment. Regulatory Affairs J 2006;16:291-4.

25. Amrit B Karmarkar. Effect of ceolus K G-802 on the dissolution rate of fenofibrate liquisolid tablets: pre-formulation and formulation development studies. Drug Discoveries Ther 2010;4;493-8.

26. Khanfar M, Sheikh SM, Faiza K. Preparation of the sustainedrelease dosage form of Venlafaxine $\mathrm{HCl}$ using liquisolid technique. Pharm Dev Technol 2014;19:103-15.

27. Singh SK, Prakash D, Srinivasan KK, Gowthamarajan K. Liquisolid compacts of glimepiride: an approach to enhance the dissolution of poorly water soluble drugs. J Pharm Res 2011;4:2263-8

28. United States Pharmacopeia. 30ed. Rockville: United States Pharmacopeia Convention; 2008.

29. Bala R, Khanna S, Pawar P. Polymers in fast disintegrating tablets-a review. Asian J Pharm Clin Res 2012;5:8-14.

30. Vraníková B, Gajdziok J, Doležel P. The effect of super disintegrants on the properties and dissolution profiles of liquisolid tablets containing rosuvastatin. Pharm Dev Technol 2015;23:1-10.

31. Jagdale SC, Fernandes NC, Kushekar BS, Shah TP, Chabukswar AR. Selection of super disintegrant for Famotidine rapidly disintegrating tablets. J Chem Pharm Res 2010;2:65-72.

32. Thoorens G, Krier F, Leclercq B, Carlin B, Evrard B. Microcrystalline cellulose, a direct compression binder in quality by design environment-a review. Int J Pharm 2014;473:64-72.

33. Padmapreetha J, Arulkumaran KSG. Improvement of dissolution rate of diacerein using liquisolid technique. J Chem Pharm Res 2016;8:209-19.

34. Javadzadeh Y, Shariati H, Movahhed-Danesh E, Nokhodchi A. Effect of some commercial grades of microcrystalline cellulose on flowability, compressibility, and dissolution profile of piroxicam liquisolid compacts. Drug Dev Ind Pharm 2009;35:243-51.

\section{How to cite this article}

- Mustafa Egla, Shaimaa N Abd Al Hammid. Design zolmitriptan liquisolid orodispersible tablets and their in vitro evaluation. Int J Pharm Pharm Sci 2017;9(1):297-303. 